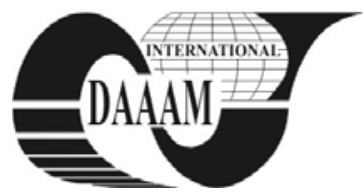

Annals of DAAAM for 2011 \& Proceedings of the 22nd International DAAAM Symposium, Volume 22, No. 1, ISSN 1726-9679 ISBN 978-3-901509-83-4, Editor B. Katalinic, Published by DAAAM International, Vienna, Austria, EU, 2011 Make Harmony between Technology and Nature, and Your Mind will Fly Free as a Bird Annals \& Proceedings of DAAAM International 2011

\title{
REMOTE AND VIRTUAL LABS IN A DISTANCE LEARNING ENVIRONMENT
}

\author{
SEILER, S[ven]; PTASIK, D[ennis] \& SELL, R[aivo]
}

\begin{abstract}
Remote and Virtual Labs are currently important research aspects, not only in the European Seventh Framework Programme with its "Technology-enhanced learning" scheme, but also in all levels of education. Especially schools and universities are facing major problems trying to keep up their practical labs and experiments with the industry's rapid technological development. Modern online versions of cuttingedge technology are necessary to be up-to-date in educating young students. These challenges are especially tough to solve concerning engineering domains, since the therefor required labsare often very expensive. This paper is presenting the ongoing research by a consortium of European universities, mainly involving researchers from Germany and Estonia, dealing with distance learning approaches, to encounter the problems named above
\end{abstract}

Key words: distance lab, remote lab, remote engineering, virtual lab, mechatronic, virtualization

\section{INTRODUCTION}

Today's Computer Science and Electrical engineering industry is characterized by rapidly occurring innovations and continuous advancement of existing technologies. Therefore it is quite a challenge for higher education institutions, especially the vocational and third ones, to keep up with the high pace of technological advancements. Furthermore, European countries are facing the emerging competition from Asian countries. The education has to be made more attractive to young people and feasible to full-time employees in order to stabilize the European leadership in product development and to compete successfully with overseas-countries. Serious problems, within the practical learning process, occur in the vocational higher education system itself. For engineering education institutions the main problem is the availability of (often expensive) ICT based learning material for the classes, the lack of functional qualified teachers, and also the lack of places in classes for capacious equipment. Another common problem is to exploit new Internet technology for practical education in these fields.

The consortium of universities from Germany, Estonia, Finland, United Kingdom, France, Sweden and Lithuania encounter these problems by the intensive research in Distance Learning. This endeavor is accompanied by the development of modern web-based Remote Lab solutions, which are presented in this paper.

While a lot of different Remote Labs, for example those presented by (Odeh, 2010) and (Agrawal \& Cherner, 2008) are existing in the education of young engineers, they are mainly focused on bringing one specific experiment / lab to the web. While the general approach of remote experiments is fulfilled, these kinds of labs are often proprietary and limited in their possibility to be interfaced by other platforms.

\section{CONCEPT FOR DISTANCE LEARNING}

The envisaged consortium is seeking for a wider approach, attempting to provide accessibility to any desired lab over the Internet. In the frame of three consecutive Leonardo da Vinci projects, named Interstudy (Advanced E-Curricula and Mobile Tools for Interdisciplinary Modular Study, 2007), Autostudy (Modularization of the automotive study process by eenvironment, 2009) and the current project MoRobE (Modern Shared Robotic Environment, 2010) an universal approach for

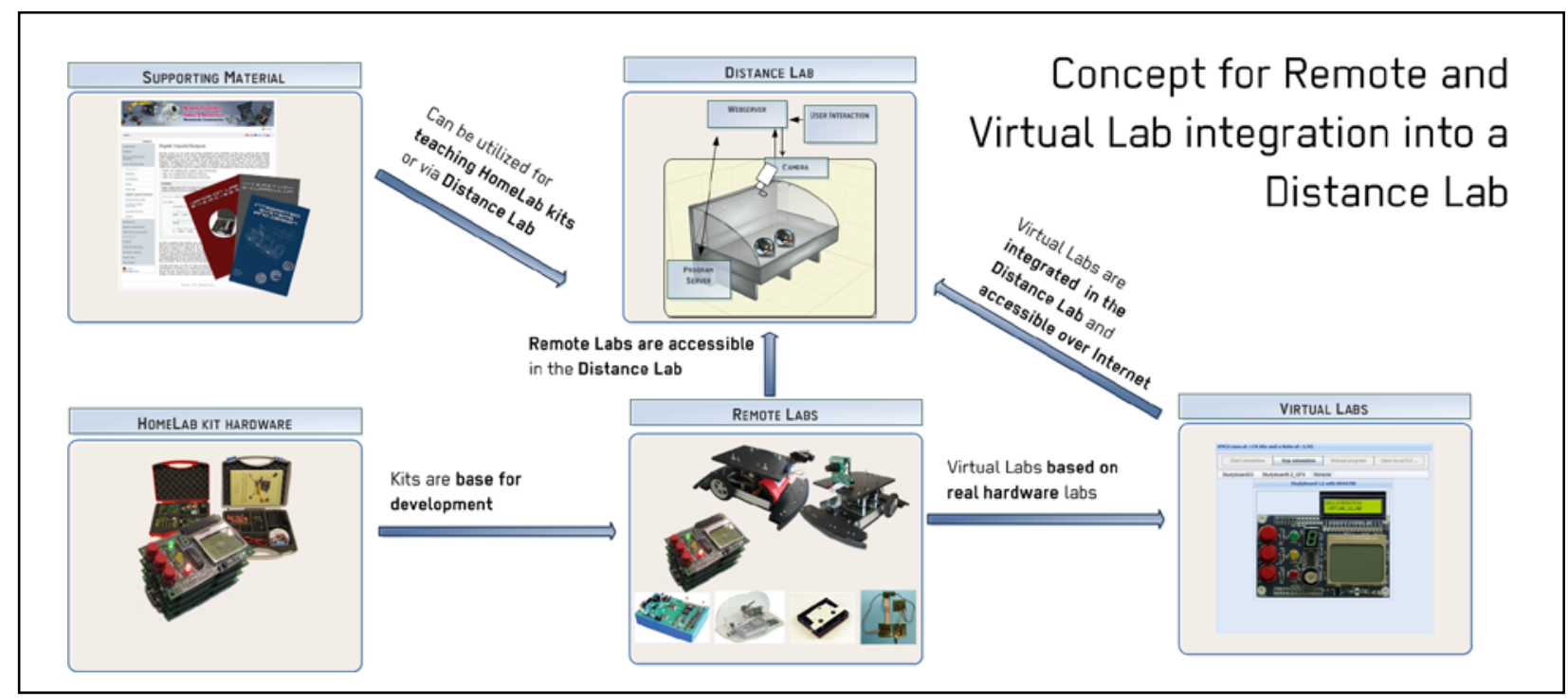

Fig. 1. Concept for Remote and Virtual Lab integration into a Distance Lab 
integrating any desired lab into a web environment was developed. This objective will be presented in the following parts of this paper.

The comprehensive concept is illustrated in figure 1 . Initially, the main idea was built upon the Home Lab kits hardware, self-developed hardware packages, presented by (Sell \& Seiler, 2010) and (Sell \& Seiler, 2011) in detail. While performing in project Interstudy, this undertaking was widened to a more generic approach, to enable also other hardware being accessible over the Distance Lab web platform.

\section{REMOTE LABS}

The original idea of Interstudy was based on the HomeLab kits to integrate them into a web platform, called Distance Lab. As this approach was taken-up quite positive by receivers, the consortium decided to extend this idea by new hardware in the two following projects Autostudy and MoRobE. Some examples of integrated hardware, currently accessible through the Distance Lab are illustrated in figure 1, at the Remote Lab section. These consist for example of a windshield wiper system, different kinds of robotic applications, other CAN based labs and some rather old-fashioned labs from engineering department in Tallinn University of Technology.

\section{VIRTUAL LAB}

The second method to realize a proper distance lab is the concept of virtual laboratories, where simulated versions of commonly used lab-hardware is provided over the Internet. These virtual labs are exact copies of real labs used in Universities or vocational education Institutions. The solution presented in this paper is based on a web based virtual micro controller, as described in (Seiler \& Sell, 2011) and (Bölter, 2010). In addition we have created plenty of virtual hardware that can be plugged to the controller. The whole system is a modular software framework that contains enhanced controller modules as well as add-on components like displays, LEDs, motors. To use this framework in studies, the handling of all virtual components was designed very similar to real hardware. The idea was that students can develop software using a regular programming tool (like AVR Studio) and run this software on virtualized hardware. Since the program code will be developed with a standard tool, it will work on real hardware as well as it does on virtual hardware. These way students get practical experience in programming that can be applied to real world problems and applications but they fully rely on expensive lab times.

\section{DISTANCE LAB}

The developed DistanceLab solution is intended for educational use. It consists of a web interface and a set of hardware, providing access to microcontroller based systems, which can, but must not, be based upon the HomeLab Kit hardware. The DistanceLab is designed for facilitating direct programming of the connected devices. This is realized by using a programming editor and an automatically invoked compiling process; enabling flashing programs to the connected devices over the Internet. Some examples for interfaced labs are the robotic applications (via wireless flashing), specific versions of HomeLab Kits with add-on modules for a specific purpose (for example automotive study CAN-Module, LCD Display or a motor board) or the Virtual Micro Controller System with its various modules.
In case of real hardware labs, the user can monitor the behavior and control the compiled program by accessing cameras showing the lab in real time. In case of virtual hardware, specific pieces of software are used for the user interface, to captivate young engineers.

\section{CONCLUSION}

This paper describes a way to offer distance learning possibilities in form of Virtual Labs and Remote Labs accessible through the Internet in any common web browser. It is intended to develop this concept further and work on a unified interface for integrating any kind of lab into the platform. On the other hand the consortium is also focusing on transferring the concept to other educational institutions all over Europe and also into new domains (e.g. from Mechatronics to Computer Science sector). It is also planned to widen the network of labs and offer other institutions to integrate their own labs into a common platform.

\section{ACKNOWLEDGEMENTS}

Some parts of the work are supported by Lifelong Learning Programme projects (e.g. DE/09/LLP-LdV/TOI/147252) and ETF grant G8652.

\section{REFERENCES}

Odeh, S. (2010). Building Reusable Remote Labs with Adaptable Client User-Interfaces. JOURNAL OF COMPUTER SCIENCE AND TECHNOLOGY Volume: 25 Issue: 5 pp 999-1015, ISSN: 1000-9000

Agrawal, JP.;Cherner, YE (2008). A Classroom/Distance Learning Engineering Course on Optical Networking with Virtual Lab. 2008 IEEE Region 8 International Conference on Computational Technologies in Electrical and Electronics Engineering. Novosibirsk, Russia, 2008

*** (2007) http://interstudy.ttu.ee/ - The Advanced E-Curricula and Mobile Tools for Interdisciplinary Modular Study website, Accessed on: 2011-08-08

*** (2009) http://autostudy.eu/ - Modularization of the automotive study process by e-environmentwebsite, Accessed on: 2011-08-08

*** (2010) http://morobe.eu/ - Modern Shared Robotic Environment website, Accessed on: 2011-08-10

Sell, R.; Seiler, S. (2010). Combined Robotic Platform for Research and Education. SIMPAR 2010 Workshops Intl. Conf. on SIMULATION, MODELING and PROGRAMMING for AUTONOMOUS ROBOTS, Darmstadt (Germany) November 15-16, 2010, ISBN 978-300-032863-3, pp. 522-531

Sell, R.; Seiler, S. (2011). Integrated Concept for embedded system study, Prodeedings of the 7th International Conference Mechatronic Systems and Materials (MSM 2011), 7 - 9 July, 2011, Kaunas, Lithuania, ISSN 18228283

Seiler, S.; Sell, R. (2011). Comprehensive Blended Learning Concept for Teaching Micro Controller Technology, Proceedings of the 4th International eLBa Science Conference, Rostock (Germany) May 26-27, 2011, ISBN 978-3-8396-0258-4, pp. 15-24

Bölter, M. (2010). Virtual $\mu$ CLab: Entwicklung einer Simulationssoftware für eine webbasierte Mikrocontroller Lernumgebung, Diploma Thesis, Bochum University of Applied Sciences, Bochum, Germany, 2010 